\title{
CARACTERÍSTICAS SIMBIÓTICAS E FENOTÍPICAS DE Azorhizobium doebereinerae, MICROSSIMBIOTE DE Sesbania virgata ${ }^{1}$
}

\author{
Ligiane Aparecida Florentino² e Fátima M. S. Moreira ${ }^{3}$
}

\begin{abstract}
RESUMO - Foram realizados quatro experimentos em casa de vegetação. O primeiro e o segundo experimentos tiveram por objetivo verificar a capacidade de nodulação e a eficiência simbiótica de Sesbania virgata com estirpes de rizóbio homólogas (isoladas de nódulos da mesma espécie inoculada com amostras de solos da floresta amazônica e do Sudeste brasileiro, identificadas como Azorhizobium doebereinerae) e com estirpes de rizóbio isoladas de outras espécies de leguminosas. No terceiro e quarto experimentos, o objetivo foi analisar se a presença de A. doebereinerae em solos de diferentes ecossistemas, em dois municípios do Sul de Minas Gerais, estava relacionada com a presença de $S$. virgata. Em todos os experimentos foram adicionados três tratamentoscontrole para verificar a ausência de contaminação e adequação das condições experimentais para expressão da eficiência simbiótica, além servirem de referências para comparação dos demais tratamentos. Dois controles foram sem inoculação: um sem nitrogênio mineral e outro em que foi adicionado nitrogênio mineral (35 mg. $\mathrm{L}^{-}$ ${ }^{1} \mathrm{~N}-\mathrm{NH}_{4} \mathrm{NO}_{3}$ ). No terceiro controle, foi inoculada a estirpe BR $5401^{\mathrm{T}}$, recomendada como inoculante para $S$. virgata e também estirpe tipo de $A$. doebereinerae. Os tratamentos foram aplicados sete dias após a repicagem das sementes para os frascos de vidro contendo $800 \mathrm{~mL}$ de solução nutritiva sem nitrogênio, onde permaneceram durante 50 dias. Objetivou-se, ainda, estudar a diversidade cultural e fenotípica de isolados de A. doebereinerae de solos da Amazônia e dos isolados obtidos nos experimentos III e IV. No primeiro e segundo experimentos, verificou-se que $S$. virgata somente nodulou quando foi inoculada com estirpes de rizóbio homólogas. No terceiro e quarto experimentos, observou-se que $S$. virgata nodulou somente com a inoculação de amostras de solos coletadas próximas de $S$. virgata. Concluiu-se que os isolados de A. doebereinerae de solos da Amazônia e os isolados dos experimentos III e IV, de solos de Minas Gerais, apresentaram alta similaridade simbiótica e fenotípica entre si e com a estirpe BR $5401^{\mathrm{T}}$ e a simbiose entre $S$. virgata e A. doebereinerae, independentemente da estirpe, foi altamente eficiente.
\end{abstract}

Palavras-chave: Simbiose rizóbio-leguminosa, espécie arbórea tropical e fixação biológica de $\mathrm{N}_{2}$.

\section{SYMBIOTIC AND PHENOTYPIC CHARACTERISTICS OF Azorhizobium doebereinerae, MICROSYMBIONT OF Sesbania virgata}

\begin{abstract}
Four experiments were carried out under greenhouse conditions. The first and second experiments aimed to evaluate the nodulation capability and symbiotic efficiency of $\boldsymbol{S}$. virgata $\left(N_{2}\right.$ fixation) with homologous rhizobia strains (isolated from nodules of the same species after inoculation with soil samples from the Amazon forest or from southeastern Brazil, and identified as Azorhizobium doebereinerae) and with rhizobia strains isolated from nodules of other leguminous species. The third and fourth experiments aimed to verify whether the presence of A. doebereinerae in soils of different ecosystems of two municipalities in southern Minas Gerais is related with the occurrence of $\boldsymbol{S}$. virgata. The four experiments comprised treatments inoculating different strains (experiments I and II) or inoculating soil suspensions of composed samples collected from different ecosystems of southern Minas Gerais, including areas where S. virgata occurred (experiments III and IV). All the experiments had three control treatments to verify the absence of contamination and suitability of
\end{abstract}

\footnotetext{
${ }^{1}$ Recebido em 24.09.2007 e aceito para publicação em 06.03.2009.

${ }^{2}$ Programa dePós-Graduação em MicrobiologiaAgrícola da Universidade Federal de Lavras (UFLA). E-mail: <ligiflorentino@ yahoo.com.br> .

${ }^{3}$ Departamento de Ciência do Solo da UFLA e bolsista produtividade em pesquisa do CNPq. E-mail: <fmoreira@ufla.br>.
} 
experimental conditions for symbiotic efficiency expression, besides being references for comparison of the other treatments. Two control treatments were without inoculation, with and without mineral nitrogen (35 mg. $\left.L^{-1} \mathrm{~N}-\mathrm{NH}_{4} \mathrm{NO}_{3}\right)$. The third control treatment was inoculated with strain BR $5401^{T}$, recommended as inoculant for $\boldsymbol{S}$. virgata and also the type strain A. doebereinerae. Treatments were applied to previously germinated seeds transferred to dark glass vials with $800 \mathrm{~mL}$ of nutrient solution without nitrogen, where plants where allowed to grow during 50 days. In the first and second experiments it was verified that $\mathbf{S}$. virgata only nodulated when inoculated with homologous rhizobia strains, i.e., strains isolated from nodules of the same species. In the third and fourth experiments, it was verified that $\mathbf{S}$. virgata would nodulate only when inoculated with soil samples collected close to $\mathbf{S}$. virgata plants. It was concluded that A. doebereinerae isolates from the Amazonia and Minas Gerais soils presented high phenotypic and symbiotic similarity among them and BR $5401^{T}$ and that $\boldsymbol{S}$. virgata and A. doebereinerae symbiosis is highly specific and efficient for all strains.

Keywords: Legume-rhizobia symbiosis, tropical tree species and biological nitrogen fixation $N_{2}$.

\section{INTRODUÇÃO}

A família Leguminosae (ou Fabaceae) possui cerca de 20.000 espécies e apresenta grande potencial de utilizações econômicas e ambientais, como exploração de madeira, celulose, forragem, adubação verde, lenha e carvão, e na recuperação de áreas degradadas por meio do estabelecimento de determinadas espécies em solos de baixa fertilidade natural. Grande parte dessas espécies é capaz de se associar com bactérias que fixam o $\mathrm{N}_{2}$ atmosférico, geralmente chamadas de rizóbio, possibilitando a manutenção de níveis adequados de nitrogênio $(\mathrm{N})$ para o crescimento vegetal e dispensando total ou parcialmente o uso de fertilizantes nitrogenados que, além de caros, podem exercer impactos sobre o ecossistema.

Uma das espécies dessa família, com grande potencial para recuperação de áreas degradadas, é a Sesbania virgata (syn. S. marginata), conhecida popularmente como "saranzinho", “mãe-josé” e "feijãozinho"; um arbusto perene com 1 a 4 m de altura, que floresce e frutifica durante quase todo o ano. Essa espécie é nativa da parte sul do Continente americano, ocorrendo nas Regiões Sul, Sudeste e Centro-Oeste do Brasil e no Paraguai, Argentina e Uruguai (POTT e POTT, 1994). É considerada espécie bastante rústica devido a sua tolerância a condições de baixa oxigenação e a solos com baixa fertilidade natural, o que favorece sua utilização no reflorestamento de matas ciliares e na recuperação de solos degradados (ALLEN e ALLEN, 1981; FRANCO et al., 1996). Coutinho et al. (2006) e Chaves et al. (2003) relataram que as mudas de $S$. virgata desenvolvem-se bem em substratos de resíduos industriais sem adição de fertilizantes.

R. Árvore, Viçosa-MG, v.33, n.2, p.215-226, 2009
Segundo Pott e Pott (1994), essa planta pode ser utilizada ainda na atividade apícola e como fornecedora de lenha. Na Argentina, a semente torrada substitui o café, sendo "café" um dos nomes populares. Kissmann (1992, 1999) e Lorenzi (2000) descreveram essa espécie como infestante de áreas úmidas ou alagadas, incluindo lavouras de arroz irrigado e pastagem e contendo compostos tóxicos (principalmente as sementes), que podem causar problemas ao gado. Já Braggio et al. (2002) demonstraram que $S$. virgata têm propriedades farmacológicas, pois o tratamento oral com sumo liofilizado das folhas em camundongos diminuiu a reação ao estímulo doloroso e reduziu o edema inflamatório.

Essa espécie estabelece simbiose com o rizóbio da espécie Azorhizobium doebereinerae (syn. A. johannae) (GONÇALVES e MOREIRA, 2004; MOREIRA et al., 2006), fixando nitrogênio suficiente para o seu desenvolvimento. Esses mesmos autores relataram a ocorrência de uma relação de alta especificidade entre S. virgata e seu microssimbionte. O gênero Azorhizobium atualmente contém apenas duas espécies: $A$. caulinodans (DREYFUS et al., 1988) e A. doebereinerae (MOREIRA et al., 2006). O gênero Azorhizobium pode facilmente ser distinguido de outras espécies de bactérias que nodulam leguminosas em meio de cultura $79 \mathrm{com}$ o indicador de $\mathrm{pH}$ azul de bromotimol (YMA) (FRED e WAKSMAN, 1928; VINCENT, 1970), pois tem crescimento rápido, alcaliniza o meio e produz escassa quantidade de goma. Já a espécie $A$. dobereinerae pode ser distinguida de $A$. caulinodans, pois não forma nódulos caulinares em $S$. rostrata, nem induz nódulos eficientes nas suas raízes, e A. caulinodans (estirpe ORS 571 ${ }^{\mathrm{T}}$ ) só induz pseudonódulos que não fixam nitrogênio nas raízes de $S$. virgata (GONÇALVES e MOREIRA, 2004). 
Essas características específicas permitem a identificação dessas espécies com métodos relativamente rápidos e acessíveis a laboratórios com infraestrutura básica e poucos recursos financeiros, facilitando estudos da ecologia de suas simbioses.

Os objetivos deste trabalho foram: 1) verificar as características simbióticas de $S$. virgata com estirpes de rizóbio homólogas (isoladas de solos da floresta amazônica e do Sudeste brasileiro e identificadas como A. doebereinerae) e com estirpes de rizóbio isoladas de outras espécies de leguminosas; 2) analisar se a presença de $A$. dobereinerae em solos de diferentes ecossistemas do Sul de Minas Gerais está relacionada com a presença de S. virgata; e 3) estudar a diversidade fenotípica, por meio de eletroforese em gel de poliacrilamida (SDS-PAGE), de isolados de A. doebereinerae de solos da Amazônia e do Sul de Minas Gerais.

\section{MATERIAL E MÉTODOS}

\section{Características gerais comuns aos quatro} experimentos de caracterização simbiótica

O trabalho foi composto por quatro experimentos instalados em casa de vegetação no período de dezembro de 2004 a maio de 2005, no Departamento de Ciência do Solo da Universidade Federal de Lavras (UFLA). Sesbania virgata foi cultivada em frascos de vidro escuro reciclado (originalmente usado com reagentes líquidos) com capacidade para $1 \mathrm{~L}$ contendo $800 \mathrm{~mL}$ de solução nutritiva de Jensen (1942) sem nitrogênio $\left(\mathrm{CaHPO}_{4} 1 \mathrm{gL}^{-1}, \mathrm{~K}_{2} \mathrm{HPO}_{4} 0,2 \mathrm{gL}^{-1}, \mathrm{MgSO}_{4} .7 \mathrm{H}_{2} \mathrm{O} 0,2\right.$ $\mathrm{gL}^{-1}, \mathrm{NaCl} 0,2 \mathrm{gL}^{-1}, \mathrm{FeCl}_{3} 0,1 \mathrm{gL}^{-1}, \mathrm{H}_{3} \mathrm{BO}_{3} 2,86 \mathrm{mgL}^{-1}$, $\mathrm{MnSO}_{4} \cdot 4 \mathrm{H}_{2} \mathrm{O} 2,03 \mathrm{mgL}^{-1}, \mathrm{ZnSO}_{4} .7 \mathrm{H}_{2} \mathrm{O} 0,22 \mathrm{mgL}^{-1}$, $\left.\mathrm{CuSO}_{4} \cdot 5 \mathrm{H}_{2} \mathrm{O} 0,08 \mathrm{mgL}^{-1} \mathrm{e} \mathrm{Na} \mathrm{MoO}_{4} \cdot \mathrm{H}_{2} \mathrm{O} 0,09 \mathrm{mgL}^{-1}\right)(\mathrm{pH}$ $6,8)$ e esterilizada. Cada frasco continha no seu interior uma folha de papel-filtro retangular $(3 \times 25 \mathrm{~cm})$. que serviu de suporte e condução de solução para as raízes, principalmente quando elas ainda estavam pequenas. Os frascos foram hermeticamente tampados com papelalumínio para evitar contaminação. Nessas tampas foram feitos dois orifícios adjacentes: um para introdução de uma ponteira de micropipeta $(1 \mathrm{~mL})$, que continha algodão na parte superior para impedir a entrada de contaminação, e por onde foram introduzidos posteriormente, retirando-se algodão, os respectivos inóculos (cultura de estirpe ou suspensões de solo) ou solução de nitrogênio mineral e outro orifício feito assepticamente no momento de inserção da radícula da semente germinada (Figura 1). Antes do plantio, foi realizada a quebra de dormência das sementes por imersão em ácido sulfúrico durante 50 min, seguida da lavagem em água esterilizada. Em seguida, essas foram colocadas em placas contendo algodão e papelfiltro umedecidos esterilizados em autoclave. Após a germinação, foi retirado o tegumento das sementes, sendo, a radícula introduzida em orifício da tampa de papel-alumínio do frasco de vidro contendo solução nutritiva. Cada frasco de vidro recebeu uma semente germinada de $S$. virgata.
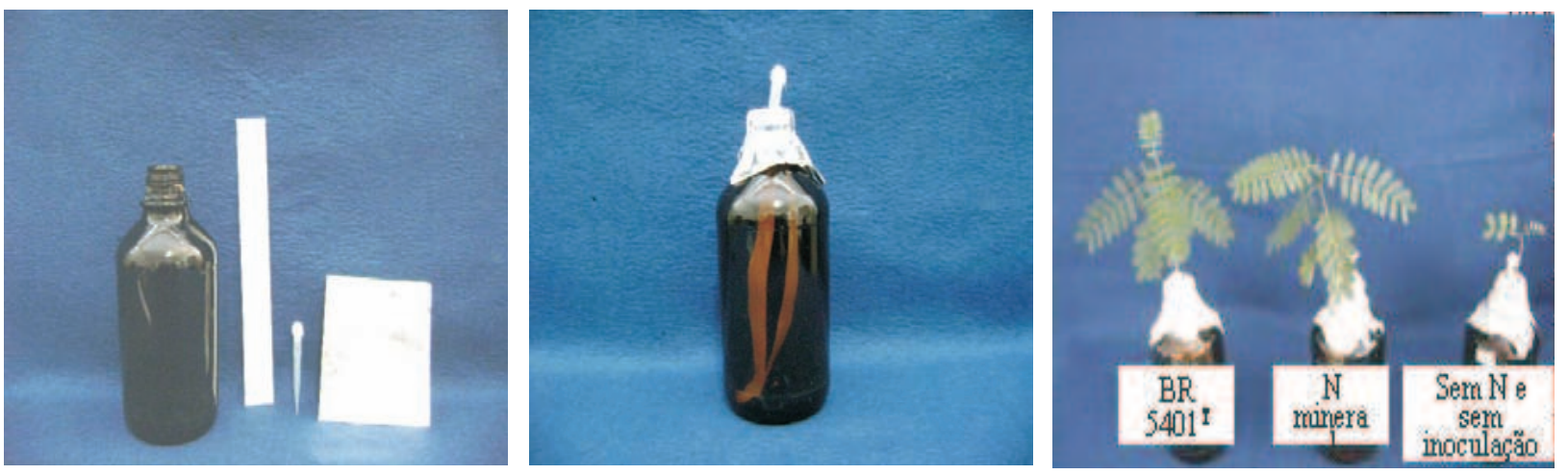

Figura 1 - Materiais utilizados para o preparo dos frascos contendo solução nutritiva de Jensen (1942) sem nitrogênio onde Sesbania virgata foi cultivada (A); Frasco sem a planta (B); Frascos contendo S. virgata inoculada com a estirpe BR $5401^{\mathrm{T}}$, com $\mathrm{N}$ mineral $\left(35 \mathrm{mg} \mathrm{kg}^{-1}\right)$ e sem $\mathrm{N}$ e sem inoculação (C).

Figure 1 -Materials used for the preparation of flasks containing Jensen nutritive solution (1942) without nitrogen where Sesbania virgata was grown (A); Flask without the plant (B); Flasks containing the control treatments in $S$. virgata: inoculation with the strains BR $5401^{T}$, without inoculação, with mineral $N\left(35 \mathrm{mg} \mathrm{kg}^{-1}\right)$ e without mineral $N(C)$. 
Para a inoculação das plantas, todas as estirpes, inclusive a BR 5401 ${ }^{\mathrm{T}}$, foram cultivadas em meio de cultura líquido 79 com azul de bromotimol e com pH 6,8 (FRED e WAKSMAN, 1928), sob agitação por três dias, e cada planta foi inoculada com $1 \mathrm{~mL}$ de meio de cultura na fase log com $10^{9} \mathrm{UFC}$ (unidades formadoras de colônias) $\mathrm{mL}^{-1}$. Nas amostras de solo, $50 \mathrm{~g}$ de solo de cada amostra composta foram suspensas em $50 \mathrm{~mL}$ de solução salina $(\mathrm{NaCl} 0,55 \%)$ e submetidas à agitação por $30 \mathrm{~min}$, a $50 \mathrm{rpm}$, e $1 \mathrm{~mL}$ de cada suspensão foi inoculada em cada planta.

Em todos os experimentos foram adicionados três tratamentos-controle para verificar a ausência de contaminação e adequação das condições experimentais para expressão da eficiência simbiótica, além de servirem de referências para comparação dos demais tratamentos. Dois desses controles não foram inoculados: um não recebeu nitrogênio mineral e no outro se adicionou nitrogênio mineral ( $35 \mathrm{mg} . \mathrm{L}^{-1} \mathrm{~N}-\mathrm{NH}_{4} \mathrm{NO}_{3}$ ) No terceiro controle foi inoculada a estirpe BR $5401^{\mathrm{T}}$, indicada como inoculante para $S$. virgata pela EMBRAPAAgrobiologia (FARIA e MELO, 1998), recomendada pela RELARE, aprovada pelo MAPA e, também, estirpe tipo de $A$. doebereinerae (MOREIRA et al., 2006).

Utilizou-se o delineamento experimental inteiramente casualizado com 3 repetições, sendo as plantas avaliadas 50 dias após o plantio. No experimento I, foram avaliadas a matéria seca da parte aérea (MSPA) e a presença ou não de nódulos. Nos experimentos 2, 3 e 4, foram avaliados a MSPA, a matéria seca dos nódulos (MSN) e o número de nódulos (NN). Os dados de MSPA, MSN e NN foram comparados pelo teste de Skott-Knott a $5 \%$ de probabilidade.

\section{Experimento 1}

No primeiro experimento, conduzido de dezembro de 2004 a janeiro de 2005, testaram-se estirpes homólogas de $S$. virgata e estirpes dos gêneros Bradyrhizobium e Azorhizobium, incluindo estirpes referência e tipo de espécies de rizóbio, sendo a estirpe ORS $571^{\mathrm{T}}$ testada como um quarto-controle para verificação da reprodutibilidade, visto que já havia sido testada anteriormente (GONÇALVES e MOREIRA, 2004) (Tabela 1). O gênero Bradyrhizobium foi testado, pois, entre os gêneros que nodulam leguminosas, é o que apresenta maior afinidade filogenética com Azorhizobium (MARTINEZ-ROMEROeCABALLERO-MELLADO, 1996). A maior parte dessas estirpes foi selecionada por apresentarem similaridade com algumas características culturais de A. doebereinerae, como alcalinização do meio de cultura e pouca produção de goma. Já as estirpes V6 e I1 1 foram testadas visando à sua autenticação como espécies nodulíferas de $S$. virgata, pois constavam da coleção como isoladas dessa espécie, mas apresentando características culturais distintas de $A$. doebereinerae.

Tabela 1 - Espécie de rizóbio, espécie hospedeira original e características culturais das estirpes de rizóbios utilizadas no primeiro experimento

Table 1 - Rhizobium species, original host species and cultural characteristics of rhizobia strains used in the experiment

\begin{tabular}{|c|c|c|c|c|c|c|c|}
\hline \multirow[t]{2}{*}{ Estirpe } & \multirow[t]{2}{*}{ Espécie } & \multirow{2}{*}{$\begin{array}{c}\text { Hospedeiro } \\
\text { original }\end{array}$} & \multicolumn{5}{|c|}{ Características culturais (YMA pH 6,8) } \\
\hline & & & $\mathrm{ACI}^{(1)}$ & $\mathrm{pH}^{(2)}$ & Goma $^{(3)}$ & $\mathrm{AI}^{(4)}$ & $\mathrm{COR}$ \\
\hline BR $5401^{\mathrm{T}}$ & $\begin{array}{l}\text { Azorhizobium. } \\
\text { doebereinerae }\end{array}$ & Sesbania virgata & 3 & Alcalino & Pouca & Não & $\overline{\text { Branca }}$ \\
\hline BR 5402 & A. doebereinerae & S. virgata. & 3 & Alcalino & Pouca & Não & Branca \\
\hline BR 5404 & A. doebereinerae & S. virgata & 3 & Alcalino & Pouca & Não & Branca \\
\hline BR 5405 & A. doebereinerae & S. virgata & 3 & Alcalino & Pouca & Não & Branca \\
\hline ORS $571^{\mathrm{T}}$ & A. caulinodans & S. rostrata & 3 & Alcalino & Pouca & Não & Branca \\
\hline ATCC $10324^{\mathrm{T}}$ & B. japonicum & G. hispida & 7 & Alcalino & Média & Não & Branca \\
\hline USDA $76^{\mathrm{T}}$ & Bradyrhizobium elkani & G. $\max$ & 7 & Alcalino & Média & Não & Amarela \\
\hline BR $29^{5}$ & B. elkani & Glycine $\max$ & 7 & Alcalino & Pouca & Não & Branca \\
\hline INPA $565 \mathrm{~A}$ & $\mathrm{ni}^{6}$ & Inga spp. & 7 & Alcalino & Pouca & Não & Rosa \\
\hline INPA 404B & $\mathrm{ni}^{6}$ & Enterolobium & 5 & Alcalino & Média & Não & Branca \\
\hline INPA $170 B$ & $\mathrm{ni}^{6}$ & Campsiandra & 7 & Alcalino & Média & Não & Branca \\
\hline V $6^{7}$ & ni & S. virgata & 3 & Alcalino & Média & Não & Branca \\
\hline I $11^{7}$ & $\mathrm{ni}$ & S. virgata & 2 & Ácido & Média & Não & Amarela \\
\hline
\end{tabular}

${ }^{(1)}$ tempo em dias para aparecimento de colônias isoladas, ${ }^{(2)}$ reação do meio de cultivo após crescimento de colônias, ${ }^{(3)}$ produção de goma, (4) absorção de indicador do meio de cultivo, (5) Estirpe recomendada como inoculante para a soja (6) espécie não identificada provavelmente Bradyrhizobium sp. ${ }^{(7)}$ estirpes presumivelmente isoladas de $S$. virgata, apresentando características culturais diferentes de $A$. doebereineerae, espécies não identificadas

R. Árvore, Viçosa-MG, v.33, n.2, p.215-226, 2009 


\section{Experimento 2}

No segundo experimento, conduzido de maio a junho de 2005, testaram-se a autenticidade e eficiência de 12 isolados (UFLA 01-641, UFLA 01-642, UFLA 01-643, UFLA 01-644, UFLA 01-645, UFLA 01-646, UFLA 01-647, UFLA 01-648, UFLA 01-649, UFLA 01650, UFLA 01-651, UFLA 01-652), obtidos por Jesus et al. (2005), de nódulos de $S$. virgata inoculadas com amostra de solo de área de floresta de terra firme da região amazônica (Município de Benjamin Constant, AM). Todos esses isolados apresentaram características culturais semelhantes a $A$. doebereinerae, alcalinizando o meio de cultura, com escassa produção de goma e crescimento rápido, características que possibilitam diferenciar espécies desse gênero de outros que nodulam leguminosas (DREYFUS et al., 1988; MOREIRA et al., 2006).

\section{Experimento 3}

No terceiro experimento, conduzido de março a abril de 2005, pesquisou-se a presença de $A$. doebereinerae em solos de diferentes ecossistemas do Município de Três Pontas, localizados entre as coordenadas $21^{\circ} 19^{\prime} 35^{\prime \prime}$ e $21^{\circ} 23^{\prime} 19^{\prime \prime}$ de latitude sul e $45^{\circ} 18^{\prime} 02^{\prime \prime}$ e $45^{\circ} 40^{\prime} 05^{\prime \prime}$ de longitude oeste, Sul de Minas Gerais. Foram coletadas a uma profundidade de 0-20 $\mathrm{cm}$, três amostras compostas de solo em cada uma das três áreas distintas e adjacentes: café, pastagem e pastagem com ocorrência de plantas de $S$. virgata dispersas ao longo de cursos d'água. As áreas de café e pastagem estudadas caracterizam-se por pequenas propriedades, apresentando baixo nível tecnológico. Nas áreas de café, verificou-se o cultivo intercalar de plantas anuais, como feijão, milho e amendoim. Nessas áreas, cada amostra composta foi formada por 12 subamostras coletadas dentro de uma parcela de 12 x $12 \mathrm{~m}$. Nas áreas que continham $S$. virgata, cada amostra composta constituiu-se de quatro subamostras coletadas, próximo ao caule, na projeção da copa e à distância de $4 \mathrm{~m}$ do caule de $S$. virgata, onde se esperava menor efeito da planta, considerando que essa distância estava além da projeção da copa (aproximadamente $2 \mathrm{~m}$ ).

\section{Experimento 4}

No quarto experimento, conduzido de junho a julho de 2005, pesquisou-se a presença de $A$. doebereinerae em solos de diferentes ecossistemas do Município de Ribeirão Vermelho, situado na região do Alto Rio Grande, entre as coordenadas $21^{\circ} 12^{\prime} 55^{\prime \prime}$ e $21^{\circ} 13^{\prime} 27^{\prime \prime}$ de latitude sul e $45^{\circ} 03^{\prime} 57^{\prime \prime}$ e $45^{\circ} 02^{\prime} 42^{\prime \prime}$ de longitude oeste, Sul de Minas Gerais. Coletaram-se, na profundidade de 0-20 $\mathrm{cm}$, as seguintes amostras compostas de solo em áreas adjacentes: uma sob café, duas sob mata, duas sob pastagem e três em solo com $S$. virgata nas margens das rodovias BR 354 (Lavras, acesso a Ribeirão Vermelho) e BR 381 (acesso a Ribeirão Vermelho). Neste estudo, a área de café estudada apresenta sistema de plantio adensado, não ocorrendo o cultivo de plantas anuais intercalares. Já as áreas de pastagem apresentaram as mesmas características das áreas sob pastagem estudadas no Município de Três Pontas. O procedimento para coleta das amostras de solo nas áreas com café, mata e pastagem foi semelhante àquele do experimento 3 . Para a coleta das amostras de solo nas áreas que continham $S$. virgata, cada amostra composta constituiu-se de quatro subamostras coletadas próximo ao caule, a 20 e $40 \mathrm{~m}$ de distância do caule de $S$. virgata. Essas distâncias foram escolhidas em função dos resultados do terceiro experimento, com o objetivo de verificar se a influência da planta ocorria a distâncias maiores que 4 m (distância máxima analisada no experimento 3). A conservação das amostras e inoculação das plantas seguiram os mesmos procedimentos adotados no experimento 3 .

\section{Caracterização fenotípica de isolados de $A$. doebereinerae de solos do Sul de Minas Gerais (MG) e daAmazônia (AM)}

Para verificar a presença de $A$. doebereinerae ou de outras espécies de rizóbio, de todas as plantas do terceiro e quarto experimentos que apresentaram nódulos foram retirados aleatoriamente quatro para isolamento de bactérias e verificação se as características culturais em meio 79 (YMA) (FRED e WAKSMAN, 1928; VINCENT, 1970) correspondiam às de Azorhizobium ou de outro gênero de rizóbio.

Foram obtidos os perfis de proteína total por meio de eletroforeseem geldepoliacrilamida(SDS-PAGE) de59isolados com características culturais similares a $A$. doebereinerae. Desses, 14 foram obtidos de nódulos de $S$. virgata (JESUS et al., 2005), os quais foram testados no Experimento 2, e 10 isolados foram obtidos de nódulos de siratro (Macroptillium atropurpureum) (LIMA, et al., 2009), ambos inoculados com solos da Amazônia. Os outros 35 isolados foram obtidos de nódulos de $S$. virgata inoculada com solos coletados na proximidade do caule de $S$. virgata em ecossistemas de pastagem no Sul de Minas que continham S. virgata (Experimentos 3 e 4).

R. Árvore, Viçosa-MG, v.33, n.2, p.215-226, 2009 
Para a análise de proteínas totais, as condições de cultivo foram rigorosamente padronizadas para todas as estirpes. As estirpes foram cultivadas em meio de cultura 79 por quatro dias, e posteriormente foram cultivadas por duas vezes sucessivas, em meio TY sólido, com mesmo tempo de incubação. Colônias isoladas foram inoculadas em $50 \mathrm{~mL}$ de meio TY líquido. O crescimento bacteriano foi obtido após quatro dias, sob agitação constante de $120 \mathrm{rpm}$ a $28^{\circ} \mathrm{C}$. Em seguida, o meio com cada cultura foi centrifugado a $12.000 \mathrm{rpm}$ por $10 \mathrm{~min}$, à temperatura de $4{ }^{\circ} \mathrm{C}$, e o sobrenadante foi descartado e o "pellet" formado, ressuspenso em tampão fosfato de sódio (NaPBS). Esse procedimento foi repetido duas vezes para lavagem das células. Setenta miligramas do "pellet" foi transferido para tubos de $1,5 \mathrm{~mL}$; foi adicionado $0,9 \mathrm{~mL}$ do tampão da amostra (TTA) e 0,1 mL de SDS a 20\% para solubilização das proteínas. Essa mistura foi aquecida em banho-maria a $95^{\circ} \mathrm{C}$ por $10 \mathrm{~min}$. As amostras de proteínas solubilizadas foram centrifugadas a $12.000 \mathrm{rpm}$ por $10 \mathrm{~min}$, à temperatura de $4{ }^{\circ} \mathrm{C}$, e $40 \mu \mathrm{L}$ foram submetidas à eletroforese em gel de poliacrilamida (PAGE). Para tal, foi empregado o método Laemmli (1970), com modificações descritas por Jackmam (1985), utilizadas em rizóbio por Moreira et al. (1993). Na eletroforese, utilizou-se um gel de sistema descontínuo, com concentração de poliacrilamida a $12 \%$ para o gel separador e a $5 \%$ para o gel de concentração.

\section{RESULTADOS E DISCUSSÃO}

Não foram encontrados nódulos nas plantas dos tratamentos-controle sem inoculação com ou sem nitrogênio nos quatro experimentos, indicando a ausência de contaminação por bactérias nodulíferas. A MSPA (g. planta ${ }^{-1}$ ) dos controles sem inoculação e com inoculação da BR $5401^{\mathrm{T}}$ apresentou pequena variação entre os diferentes experimentos: 0,05 a 0,09 ( $\mathrm{sem} \mathrm{N})$; 0,39-0,74 (com N) e 0,36-0,50 (BR 5401 ${ }^{\mathrm{T}}$ ) (Tabelas 2, 3,4 e 5). Como as diferentes etapas de estabelecimento e funcionamento da simbiose podem ser influenciadas pelas condições climáticas, essa pequena variação pode ser atribuída à sensibilidade da espécie às condições climáticas das diferentes épocas de condução de cada experimento. A diferença entre o controle com $\mathrm{N}$ mineral e a BR $5401^{\mathrm{T}}$ também variou entre as diferentes épocas e pode ser explicada pelo fato de que plantas em simbiose são mais sensíveis a estresses ou, no caso, condições ambientais que plantas recebendo $\mathrm{N}$-mineral. Todos os nódulos encontrados em $S$. virgata apresentaram crescimento indeterminado e coloração avermelhada em seu interior, indicando a presença da leg-hemoglobina e eficiência em fixar $\mathrm{N}_{2}$, corroborando a presença de A. doebereinerae (GONÇALVES e MOREIRA, 2004).

No primeiro experimento, somente as plantas dos tratamentos de $S$. virgata inoculadas com as estirpes BR 5402, BR 5404 e BR 5405, estirpes homólogas de $S$. virgata, apresentaram nódulos. As plantas dos tratamentos inoculadas com essas estirpes apresentaram valores de MSPA semelhantes ao dos tratamentoscontrole com $\mathrm{N}$ mineral e inoculação com a estirpe BR $5401^{\mathrm{T}}$ (Tabela 2), corroborando a alta especificidade e eficiência simbiótica entre $S$. virgata e outras estirpes de A. doebereinerae (GONÇALVES e MOREIRA, 2004). Os valores de MSPA das plantas dos tratamentos de $S$. virgata inoculadas com estirpes de rizóbio não isoladas de $S$. virgata foram semelhantes aos de MSPA do tratamento-controle sem nitrogênio e sem inoculação, uma vez que todos esses tratamentos não apresentaram nódulos e as plantas estavam em solução sem nitrogênio mineral e, portanto, com deficiência do nutriente. Esses resultados confirmam a ausência de nodulação eficiente por ORS571 $1^{\mathrm{T}}$ de A. caulinodans em S. virgata (GONÇALVES e MOREIRA, 2004). As estirpes I11 e V6 presumivelmente isoladas de nódulos de $S$. virgata não satisfizeram os postulados de Koch, ou seja, não nodularam a espécie e, portanto, se revelaram como contaminantes que surgiram no processo de isolamento ou armazenamento.

No segundo experimento, todos os tratamentos inoculados com os isolados de rizóbios de amostra de solo do Município de Benjamin Constant (AM) apresentaram nódulos, indicando que $A$. doebereinerae pode ocorrer independentemente da presença de $S$. virgata, uma vez que esta espécie não foi encontrada entre as 1.241 da família existentes nos principais herbários da região (SILVA et al., 1989). Como a amostra de solo foi coletada em floresta conhecida por sua alta diversidade de espécies de Leguminosae, provavelmente o efeito rizosférico de outras espécies tenha favorecido pelo menos a sobrevivência saprofítica da espécie, uma vez que até o momento nenhuma espécie nativa foi relatada como capaz de formar simbiose $\operatorname{com} A$. doebereinerae, ou com estirpes que possuam as características peculiares ao gênero. Recentemente, Lima et al., (2009), estudando a diversidade de rizóbios presentes em solos da Amazônia e utilizando como planta-isca o siratro, também verificou que essa espécie 
foi capaz de capturar isolados que foram identificados por meio do sequenciamento do gene $16 \mathrm{~S}$ rDNA como pertencente à espécie $A$. doebereinerae.

Os valores de MSPA das plantas dos tratamentos inoculadas com esses isolados foram semelhantes entre si e as plantas do tratamento-controle, inoculadas com a estirpe BR $5401^{\mathrm{T}}$, atualmente recomendada como inoculante para a cultura (FARIA e MELLO, 1998) (Tabela 3).

No terceiro experimento, somente as plantas dos tratamentos de $S$. virgata inoculadas com suspensão de solo de pontos coletados próximo ao caule, na projeção da copa e distanciados $4 \mathrm{~m}$ do caule de $S$. virgata, apresentaram nódulos. A inoculação das plantas com essas suspensões de solos proporcionaram valores de MSPA semelhantes aos do controle com $\mathrm{N}$ mineral e inoculado com a estirpe BR $5401^{\mathrm{T}}$ (Tabela 4), indicando que nos ecossistemas estudados a presença de $A$. doebereinerae está relacionada à ocorrência de $S$. virgata e as bactérias presentes nos nódulos são altamente eficientes em promover o crescimento vegetal. Para confirmação da presença de $A$. doebereinerae, isolaramse bactérias de quatro nódulos de cada planta e obtiveram 108 isolados, e $88 \%$ destes apresentaram características culturais semelhantes a $A$. doebereinerae. As plantas inoculadas com suspensão de solo de áreas de café e pastagem exibiram pequenas estruturas nas raízes que não se desenvolveram, como pseudonódulos, que não promoveram aumento nos valores de MSPA, sendo este semelhante ao tratamento-controle sem nitrogênio e sem inoculação (Tabela 5). Tentou-se o isolamento dos pseudonódulos, mas não foi verificado o crescimento de bactérias contaminantes em meio de cultura.

Tabela 2 - Experimento 1:Peso da matéria seca da parte aérea (MSPA) de Sesbania virgata inoculadas com estirpes de rizóbio de diferentes procedências

Table 2 - Experiment 1: Shoot dry matter weight (MSPA), of Sesbania virgata inoculated ones with strains of rhizobia from different origins

\begin{tabular}{|c|c|c|c|c|c|}
\hline Tratamento & Nodulação & $\operatorname{MSPA}\left(\right.$ g.planta $\left.{ }^{-1}\right)$ & Tratamento & Nodulação & MSPA(g.planta $\left.{ }^{-1}\right)$ \\
\hline $\mathrm{N}$ mineral ${ }^{(2)}$ & - & $0,39 \mathrm{a}^{(1)}$ & INPA 565A & - & $0,11 \mathrm{~b}$ \\
\hline sem $\mathrm{N}$ e inoculação & - & $0,08 \mathrm{~b}$ & ATCC $10324^{\mathrm{T}}$ & - & $0,11 \mathrm{~b}$ \\
\hline BR $5401^{\mathrm{T}}$ & + & 0,36 a & USDA $76^{\mathrm{T}}$ & - & $0,13 \mathrm{~b}$ \\
\hline BR 5402 & + & 0,33 a & BR 29 & - & $0,16 \mathrm{~b}$ \\
\hline BR 5404 & + & $0,34 \mathrm{a}$ & INPA 404B & - & $0,12 b$ \\
\hline BR 5405 & + & 0,35 a & INPA $170 B$ & - & $0,14 \mathrm{~b}$ \\
\hline ORS $571^{\mathrm{T}}$ & - & $0,13 \mathrm{~b}$ & I 11 & - & $0,09 \mathrm{~b}$ \\
\hline INPA $565 \mathrm{~A}$ & - & $0,11 \mathrm{~b}$ & V 6 & - & $0,11 \mathrm{~b}$ \\
\hline
\end{tabular}

${ }^{(1)}$ Médias seguidas por uma mesma letra, na coluna, não diferem entre si pelo teste de Scott-Knott a 5\%. ${ }^{(2)}$ Tratamento contendo 35 mg $\mathrm{N}-\mathrm{NH}_{4} \mathrm{NO}_{3} \mathrm{~L}^{-1}$. CV $(\%)-\mathrm{MSPA}(19,26)$.

Tabela 3 - Experimento 2: Peso da matéria seca da parte aérea (MSPA), peso da matéria seca dos nódulos (MSN) e número de nódulos (NN) de Sesbania virgata inoculada com isolados de rizóbio homólogos, obtidos da região Amazônica (município de Benjamin Constant, AM)

Table 3 - Experiment 2: Shoot dry matter weight (MSPA), nodules dry matter weight (MSN) and number of nodules (NN) of Sesbania virgata inoculated with isolates of homologous rhizobia, obtained from the Amazonia region (municipality of de Benjamin Constant, AM)

\begin{tabular}{|c|c|c|c|c|c|c|c|c|c|c|c|c|c|}
\hline \multirow{2}{*}{$\begin{array}{l}\text { Tratamento } \\
\mathrm{N} \text { mineral }^{(2)}\end{array}$} & \multicolumn{2}{|c|}{$\begin{array}{c}\text { MSPA } \\
\left(\text { g.planta }{ }^{-1}\right) \\
\end{array}$} & \multicolumn{2}{|c|}{$\begin{array}{c}\text { MSN } \\
\left(\mathrm{mg}^{\text {planta }}{ }^{-1}\right)\end{array}$} & \multicolumn{2}{|c|}{$\begin{array}{c}\text { NN } \\
\left(n^{\circ} \cdot p^{2} \operatorname{lanta}^{-1}\right)\end{array}$} & \multirow{2}{*}{$\begin{array}{c}\text { Tratamento } \\
\text { UFLA01-646 }\end{array}$} & \multicolumn{2}{|c|}{$\begin{array}{c}\text { MSPA } \\
\left.\text { (g.planta }{ }^{-1}\right)\end{array}$} & \multicolumn{2}{|c|}{$\begin{array}{c}\text { MSN } \\
\left(\mathrm{mg} \cdot \text { planta }^{-1}\right)\end{array}$} & \multicolumn{2}{|c|}{$\begin{array}{c}\mathrm{NN} \\
\left(\mathrm{n}^{\circ} \cdot \mathrm{planta}^{-1}\right)\end{array}$} \\
\hline & 0,74 & $a^{(1)}$ & 0,00 & $\mathrm{~b}$ & 0 & $\mathrm{~b}$ & & 0,34 & $\mathrm{~b}$ & 46,33 & a & 98 & a \\
\hline $\begin{array}{l}\text { Sem N } \\
\text { e inoculação }\end{array}$ & 0,09 & $\mathrm{c}$ & 0,00 & $\mathrm{~b}$ & 0 & $\mathrm{~b}$ & UFLA01-647 & 0,32 & $\mathrm{~b}$ & 59,67 & $\mathrm{a}$ & 89 & a \\
\hline $\mathrm{BR} 5401^{\mathrm{T}}$ & 0,36 & $\mathrm{~b}$ & 42,00 & a & 88 & a & UFLA01-648 & 0,38 & $\mathrm{~b}$ & 62,33 & a & 70 & a \\
\hline UFLA01-641 & 0,37 & $\mathrm{~b}$ & 44,67 & a & 110 & $\mathrm{a}$ & UFLA01-649 & 0,42 & $\mathrm{~b}$ & 44,33 & a & 77 & a \\
\hline UFLA01-642 & 0,38 & $\mathrm{~b}$ & 61,00 & a & 98 & $\mathrm{a}$ & UFLA01-650 & 0,38 & b & 50,67 & $\mathrm{a}$ & 73 & $\mathrm{a}$ \\
\hline UFLA01-643 & 0,38 & $\mathrm{~b}$ & 62,67 & a & 62 & $\mathrm{a}$ & UFLA01-651 & 0,29 & $\mathrm{~b}$ & 44,33 & $\mathrm{a}$ & 80 & a \\
\hline UFLA01-644 & 0,35 & $\mathrm{~b}$ & 55,00 & a & 95 & $\mathrm{a}$ & UFLA01-652 & 0,39 & $\mathrm{~b}$ & 52,67 & a & 91 & a \\
\hline UFLA01-645 & 0,35 & $b$ & 47,33 & $\mathrm{a}$ & 81 & $\mathrm{a}$ & & & & & & & \\
\hline
\end{tabular}

(1) Valores seguidos da mesma letra, na coluna, não diferem significativamente a 5\% de probabilidade, pelo teste de Scott-Knot; os dados de MSN e NN foram transformados para raiz quadrada $(\mathrm{x}+1) .{ }^{(2)}$ Tratamento contendo $35 \mathrm{mg} \mathrm{N}^{-} \mathrm{NH}_{4} \mathrm{NO}_{3} \mathrm{~L}^{-1}$. CV $(\%)-\mathrm{MSPA}(17,62)$; MSN (1,00); NN (12,36). 
Tabela 4 - Experimento 3: Matéria seca da parte aérea (MSPA) e dos nódulos (MSN) e número de nódulos (NN) de Sesbania virgata inoculada com suspensões de amostras de solo de diferentes ecossistemas no município de Três Pontas e próximo a plantas de $S$. virgata

Table 4-Experiment 3: Shoot dry matter weight (MSPA), nodules dry matter weight, (MSN) and number of nodules (NN) of Sesbania virgata inoculated with suspension of soil samples of different ecosystems in the municipality of Três Pontas and close to $S$. virgata plant

\begin{tabular}{|c|c|c|c|c|c|c|c|c|c|c|c|c|}
\hline \multirow{2}{*}{$\begin{array}{l}\text { Tratamento } \\
\mathrm{N} \text { mineral }^{(2)}\end{array}$} & $\begin{array}{c}\text { MSPA } \\
\left(\text { g.planta }{ }^{-1}\right)\end{array}$ & \multicolumn{2}{|c|}{$\begin{array}{c}\text { MSN } \\
\left(\mathrm{mg} \cdot \text { planta }^{-1}\right)\end{array}$} & \multicolumn{2}{|c|}{$\begin{array}{c}\mathrm{NN} \\
\left(\mathrm{n}^{\mathrm{o}} \cdot \mathrm{planta}^{-1}\right) \\
\end{array}$} & \multirow{2}{*}{$\frac{\text { Tratamento }}{4 \mathrm{~m}^{(5)} 1}$} & \multicolumn{2}{|c|}{$\begin{array}{c}\text { MSPA } \\
\left(\text { g.planta }{ }^{-1}\right)\end{array}$} & \multicolumn{2}{|c|}{$\begin{array}{c}\text { MSN } \\
\left(\mathrm{mg} \cdot \text { planta }^{-1}\right) \\
\end{array}$} & \multicolumn{2}{|c|}{$\begin{array}{c}\mathrm{NN} \\
\left(\mathrm{n}^{\circ} \cdot \mathrm{planta}^{-1}\right)\end{array}$} \\
\hline & $0,58 \quad \mathrm{a}^{(1)}$ & 0,00 & $\mathrm{c}$ & 0 & $\mathrm{e}$ & & 0,42 & $\mathrm{a}$ & 54,00 & $\mathrm{~b}$ & 53 & $\mathrm{~d}$ \\
\hline $\begin{array}{l}\text { Sem N } \\
\text { e inoculação }\end{array}$ & $0,08 \quad b$ & 0,00 & $\mathrm{c}$ & 0 & $\mathrm{e}$ & $4 \mathrm{~m} 2$ & 0,31 & $\mathrm{~b}$ & 35,00 & $\mathrm{~b}$ & 72 & $\mathrm{c}$ \\
\hline BR $5401^{\mathrm{T}}$ & 0,50 & 82,33 & $\mathrm{a}$ & 96 & $\mathrm{~b}$ & $4 \mathrm{~m} 3$ & 0,56 & $\mathrm{a}$ & 78,67 & $\mathrm{a}$ & 73 & $\mathrm{c}$ \\
\hline $\mathrm{SC}^{(3)} 1$ & 0,59 & 89,67 & $\mathrm{a}$ & 84 & $\mathrm{~b}$ & Pastagem 1 & 0,16 & b & 0,00 & $\mathrm{c}$ & 0 & $\mathrm{e}$ \\
\hline SC 2 & 0,58 & 75,67 & $\mathrm{a}$ & 101 & $\mathrm{a}$ & Pastagem 2 & 0,13 & b & 0,00 & $\mathrm{c}$ & 0 & $\mathrm{e}$ \\
\hline SC 3 & 0,39 & 47,33 & $\mathrm{~b}$ & 95 & $\mathrm{a}$ & Pastagem 3 & 0,13 & $\mathrm{~b}$ & 0,00 & $\mathrm{c}$ & 0 & e \\
\hline $\mathrm{SP}^{(4)} 1$ & 0,54 & 62,67 & b & 74 & $\mathrm{c}$ & Café 1 & 0,16 & $\mathrm{~b}$ & 0,00 & $\mathrm{c}$ & 0 & e \\
\hline SP 2 & 0,46 & 53,33 & $b$ & 81 & $\mathrm{~b}$ & Café 2 & 0,10 & $\mathrm{~b}$ & 0,00 & $\mathrm{c}$ & 0 & e \\
\hline SP 3 & 0,50 & 67,33 & $\mathrm{a}$ & 73 & $\mathrm{c}$ & Café 3 & 0,11 & b & 0,00 & $\mathrm{c}$ & 0 & $\mathrm{e}$ \\
\hline
\end{tabular}

${ }^{(2)}$ Valores seguidos da mesma letra, na coluna, não diferem significativamente a $5 \%$ de probabilidade, pelo teste de Scott-Knot; os dados

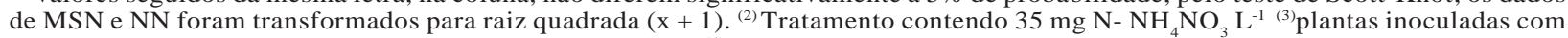
suspensão de solo coletado próximo ao caule de $S$. virgata; ${ }^{(4)}$ plantas inoculadas com suspensão de solo coletado na projeção da copa de S. virgata; ${ }^{(5)}$ plantas inoculadas com suspensão de solo coletado a 4 metros de distância do caule de $S$. virgata. CV (\%) - MSPA $(28,05) ; \operatorname{MSN}(1,00) ; \mathrm{NN}(7,00)$.

Tabela 5 - Experimento 4: Matéria seca da parte aérea (MSPA) e dos nódulos (MSN) e número de nódulos (NN) de Sesbania virgata inoculadas com suspensões de amostras de solo de diferentes ecossistemas no município de Ribeirão Vermelho e próximos à planta de $S$. virgata

Table 5 - Experiment 4: Shoot dry matter weight (MSPA), nodules dry matter weight (MSN) and number of nodules (NN) of Sesbania virgata inoculated with suspensions of soil samples from different ecossistems in the municipality of Ribeirão Vermelho and close to $S$. virgata plant

\begin{tabular}{|c|c|c|c|c|c|c|c|c|c|c|c|c|c|}
\hline \multirow{2}{*}{$\begin{array}{l}\text { Tratamento } \\
\mathrm{N} \text { mineral (2) }\end{array}$} & \multicolumn{2}{|c|}{$\begin{array}{c}\text { MSPA } \\
\left.\text { (g.planta }{ }^{-1}\right)\end{array}$} & \multicolumn{2}{|c|}{$\begin{array}{c}\text { MSN } \\
\left(\mathrm{mg} \cdot \text { planta }^{-1}\right)\end{array}$} & \multicolumn{2}{|c|}{$\begin{array}{c}\text { NN } \\
\left(n^{\circ} \cdot p^{2} \operatorname{lanta}^{-1}\right) \\
\end{array}$} & \multirow{2}{*}{$\frac{\text { Tratamento }}{40 \mathrm{~m} 1^{(5)}}$} & \multicolumn{2}{|c|}{$\begin{array}{c}\text { MSPA } \\
\left(\text { g.planta }{ }^{-1}\right) \\
\end{array}$} & \multicolumn{2}{|c|}{$\begin{array}{c}\text { MSN } \\
\left(\mathrm{mg} \cdot \text { planta }^{-1}\right)\end{array}$} & \multicolumn{2}{|c|}{$\begin{array}{c}\mathrm{NN} \\
\left(\mathrm{n}^{\mathrm{o}} \cdot \mathrm{planta}^{-1}\right)\end{array}$} \\
\hline & 0,39 & $c^{(1)}$ & 0,00 & $\mathrm{e}$ & 0 & $\mathrm{~d}$ & & 0,06 & $\mathrm{~d}$ & 0,00 & $\mathrm{e}$ & 0 & d \\
\hline $\begin{array}{l}\text { Sem N } \\
\text { inoculação }\end{array}$ & 0,05 & $\mathrm{~d}$ & 0,00 & $\mathrm{e}$ & 0 & $\mathrm{~d}$ & $40 \mathrm{~m} 2$ & 0,04 & $\mathrm{~d}$ & 0,00 & $\mathrm{e}$ & 0 & d \\
\hline BR $5401^{\mathrm{T}}$ & 0,41 & $\mathrm{c}$ & 60,00 & $\mathrm{~d}$ & 96 & $\mathrm{~b}$ & $40 \mathrm{~m} 3$ & 0,12 & $\mathrm{~d}$ & 0,00 & e & 0 & d \\
\hline $\mathrm{SC} 1^{(3)}$ & 0,86 & $\mathrm{a}$ & 105,00 & $\mathrm{a}$ & 75 & $\mathrm{c}$ & Café 1 & 0,07 & $\mathrm{~d}$ & 0,00 & $\mathrm{e}$ & 0 & d \\
\hline SC 2 & 0,89 & $\mathrm{a}$ & 93,67 & b & 167 & $\mathrm{a}$ & Mata 1 & 0,08 & d & 0,00 & e & 0 & d \\
\hline $\mathrm{SC} 3$ & 0,54 & $\mathrm{~b}$ & 78,67 & $\mathrm{c}$ & 89 & $\mathrm{~b}$ & Mata 2 & 0,07 & $\mathrm{~d}$ & 0,00 & e & 0 & d \\
\hline $20 \mathrm{~m} 1^{(4)}$ & 0,07 & $\mathrm{~d}$ & 0,00 & $\mathrm{e}$ & 0 & $\mathrm{~d}$ & Pastagem 1 & 0,12 & $\mathrm{~d}$ & 0,00 & $\mathrm{e}$ & 0 & d \\
\hline $20 \mathrm{~m} 2$ & 0,07 & $\mathrm{~d}$ & 0,00 & $\mathrm{e}$ & 0 & $\mathrm{~d}$ & Pastagem 2 & 0,11 & $\mathrm{~d}$ & 0,00 & $\mathrm{e}$ & 0 & d \\
\hline $20 \mathrm{~m} 3$ & 0,10 & $\mathrm{~d}$ & 0,00 & $\mathrm{e}$ & 0 & $\mathrm{~d}$ & & & & & & & \\
\hline
\end{tabular}

${ }^{(1)}$ Valores seguidos da mesma letra, na coluna, não diferem significativamente a 5\% de probabilidade, pelo teste de Scott-Knot; os dados de MSN e NN foram transformados para raiz quadrada $(\mathrm{x}+1)$. ${ }^{(2)}$ Tratamento contendo $35 \mathrm{mg} \mathrm{N}-\mathrm{NH}_{4} \mathrm{NO}_{3} \mathrm{~L}^{-1(3)}$ plantas inoculadas com suspensão de solo coletado próximo ao caule de $S$. virgata; ${ }^{(4)}$ plantas inoculadas com suspensão de solo coletado à 20 metros do caule de $S$. virgata; ${ }^{(5)}$ plantas inoculadas com suspensão de solo coletado à 40 metros do caule de $S$. virgata. CV (\%) - MSPA (19,46); MSN $(1,00) ; \mathrm{NN}(11,31)$.

No quarto experimento, somente as plantas dos tratamentos de $S$. virgata inoculadas com amostras de solos coletadas próximo ao caule de $S$. virgata apresentaram nódulos. A inoculação das plantas dos tratamentos de $S$. virgata com essas amostras de solos proporcionou valores de MSPA superior aos das plantas dos tratamentos-controle com $\mathrm{N}$ mineral e inoculação com a estirpe BR 5401 ${ }^{\mathrm{T}}$. Nos solos do Município de Ribeirão Vermelho, como no Município de Três Pontas, a presença de $A$. doebereinerae está relacionada à ocorrência de $S$. virgata, e as bactérias presentes nos nódulos são altamente eficientes, indicando que outras estirpes podem ser selecionadas com eficiência superior a BR $5401^{\mathrm{T}}$. Após o isolamento de quatro 
nódulos de cada planta, obtiveram-se 12 isolados com características culturais semelhantes a $A$. doebereinerae, confirmando a presença desta espécie e a alta especificidade de sua simbiose com $S$. virgata. A exemplo do que ocorreu no terceiro experimento, as plantas dos tratamentos inoculados com amostras de solo de áreas de café, pastagem e mata e com solos coletados a 20 e $40 \mathrm{~m}$ de distância do caule de S. virgata apresentaram pequenas estruturas nas raízes, pseudonódulos. Nesses tratamentos, os valores de MSPA foram semelhantes aos das plantas do tratamentocontrole sem nitrogênio e sem inoculação. Essas estruturas, quando maceradas em meio de cultura, não apresentaram crescimento.

Na figura 2, mostram-se os perfis de proteína dos 24 isolados obtidos de nódulos de $S$. virgata e siratro, inoculadas com amostras de solos da Amazônia. Observase, nessa figura, que os isolados apresentam alta similaridade entre si e com a estirpe BR $5401^{\mathrm{T}}$. Nos isolados de solos coletados na proximidade do caule de $S$. virgata (Figura 3), observa-se também que são semelhantes à estirpe BR $5401^{\mathrm{T}}$, conforme mostrado por Moreira et al. (2006) nas estirpes de A. doebereinerae.
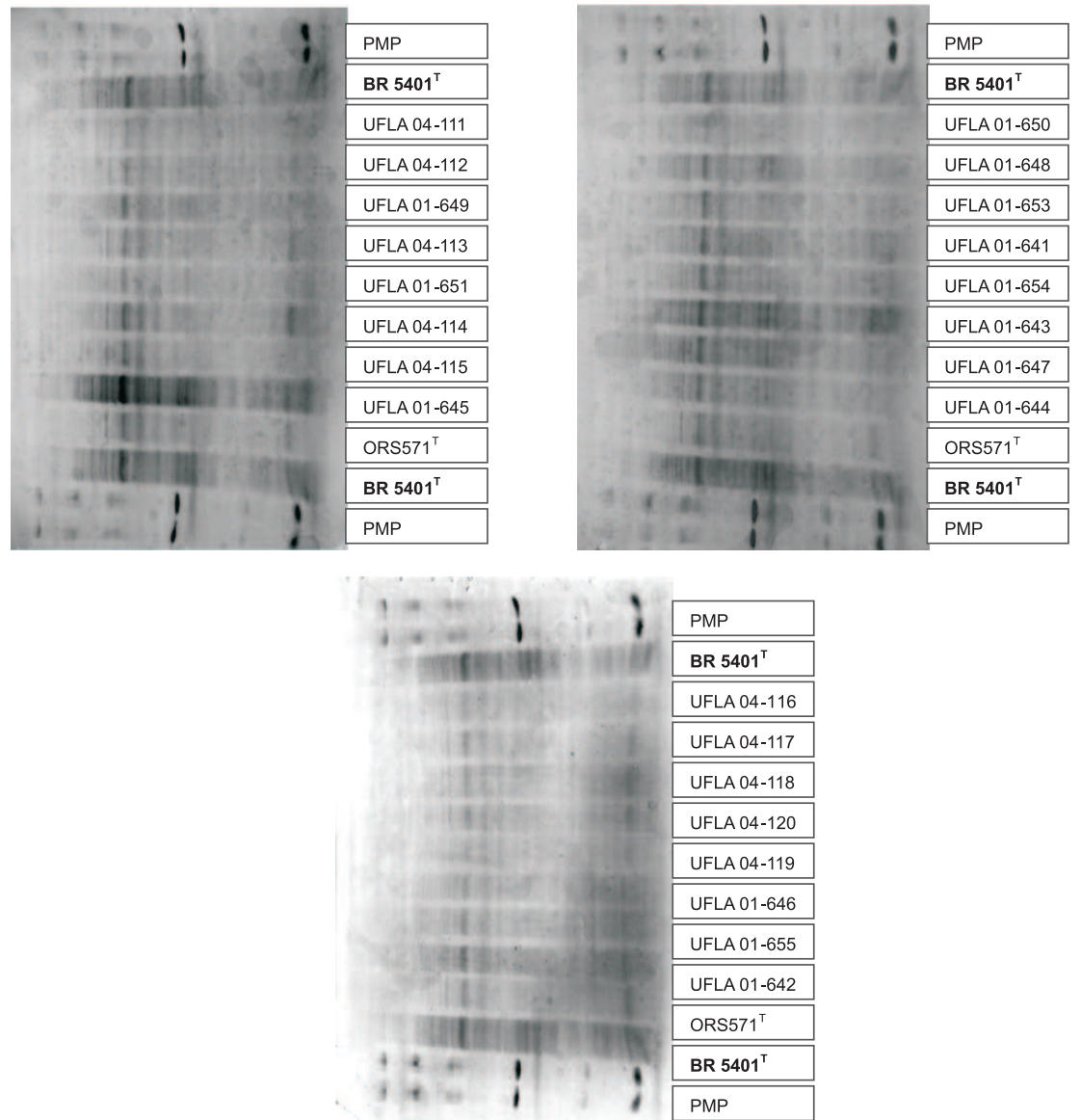

Figura 2 - Perfis de proteína celular total dos isolados obtidos de nódulos de Sesbania virgata (isolados identificados com os códigos UFLA 01-641, 642, 643, 644, 645, 646, 647, 648, 649, 650, 651, 652, 653, 654 e 655) e de Macroptilium atropurpureum (isolados identificados com os códigos UFLA 04-111, 112, 113, 114, 115, 116, 117, 118, 119 e 120) inoculados com amostras de solos da Amazônia, obtidas por eletroforese em gel de poliacrilamida (SDSPAGE). PM: padrão de peso molecular LMWM

Figure 2-Profiles of total cell protein of isolates obtained from nodules of Sesbania virgata (isolates identified with codes UFLA 01-641, 642, 643, 644, 645, 646, 647,648,649,650,651,652, 653, 654 and 655) and of Macroptilium atropurpureum (isolates identified with codes UFLA 04-111,112,113,114, 115, 116, 117, 118, 119 and 120) inoculates from Amazonia soil samples, obtained by means of electrophoresis in polyacrylamide gel (SDS-PAGE). PM: molecular weight pattern LMWM 

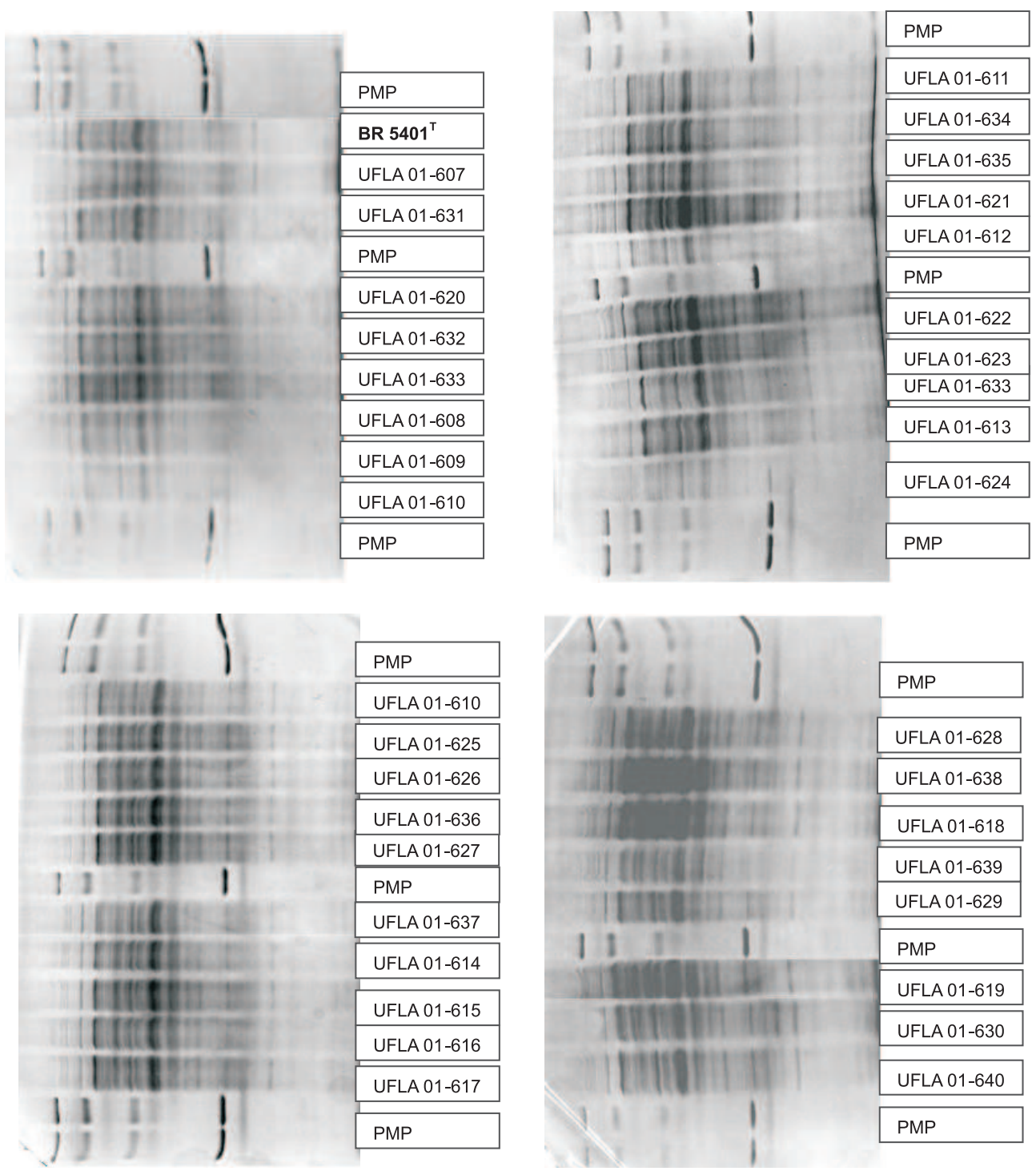

Figura 3 - Perfis de proteína celular total dos isolados obtidos de nódulos de S. virgata inoculada com amostras de solos coletadas em diferentes distâncias do caule de $S$. virgata nos municípios de Três Pontas e Ribeirão Vermelho. Os isolados identificados com os códigos UFLA 01-607, 608, 609, 610, 611, 612, 613, 614, 615, 616, 617, 618 e 619 foram obtidos de solos coletados no caule, os códigos UFLA 01-620, 621, 622, 623, 624, 625, 626, $627,628,629$ e 630 referem-se aos isolados obtidos de solos coletados na projeção da copa e os isolados com códigos UFLA 01-631, 632, 633, 634, 635, 636, 637, 638, 639 e 640 foram obtidos de solos coletados a 4 metros de distância do caule de S. virgata, das estirpes BR 5401 ${ }^{\mathrm{T}}$, de A. doebereinerae e ORS 571 ${ }^{\mathrm{T}}$, de A. caulinodans, obtidas por eletroforese em gel de poliacrilamida (SDS-PAGE). PM: padrão de peso molecular LMWM

Figure 3 - Profiles of total cell protein of isolates obtained from nodules of Sesbania virgata inoculated with soil samples collected in different distances rom the stem of $S$. virgata in the municipalities of Três Pontas and Ribeirão Vermelho, being UFLA 01-607, 608, 609, 610, 611, 612, 613, 614, 615, 616, 617, 618 and 619-isolates obtained from soil collected in the stem, UFLA 01-620, 621, 622, 623, 624, 625, 626, 627, 628, 629 and 630 - isolates obtained from soil collected in the projection of the crown and UFLA 01-631, 632, 633, 634, 635, 636, 637, 638, 639 and 640 - isolates obtained from soil collected at 4 meter distal of the stem of S. virgata, of strains BR 5401 , of A. doebereinerae and ORS $571^{T}$, of A. caulinodans, obtained by means of electrophoresis in polyacrylamide gel (SDS-PAGE). PM: molecular weight pattern LMWM

R. Árvore, Viçosa-MG, v.33, n.2, p.215-226, 2009 


\section{CONCLUSÕES}

1. Sesbania virgata nodula apenas quando inoculada com A. doebereinerae (estirpes homólogas), apresentando uma simbiose eficiente com todas as estirpes testadas.

2. Constatou-se que a ocorrência de $A$. doebereinerae em ecossistemas do Sul de Minas Gerais está relacionada com a ocorrência de $S$. virgata.

3. Os perfis de proteínas dos isolados de S. virgata apresentam alta similaridade entre si e com a estirpe BR 5401 ${ }^{\mathrm{T}}$.

\section{AGRADECIMENTOS}

Ao CNPq, pela bolsa de Iniciação Científica e de produtividade em pesquisa e adicional de bancada.

\section{REFERÊNCIAS}

ALlEN, O. N. \& ALLEN, E. K. The Leguminosae: A source book of characteristics, uses and nodulation. Wisconsin: University of Madison, 1981.813p.

BALA, A. et al. Nodulation of tree legumes and the ecology of their native rhizobial populations in tropical soils. Applied Soil Ecology, v.22, p.211-223, 2003.

BRAGGIO, M. M. et al. Atividades famacológicas das folhas da Sesbania virgata (Cav.) Arquivo do Instituo de Biologia, v.6, n.1, p.49-53, 2002.

CHAVES, L. L. B. et al. Efeitos da inoculação com rizóbio e da adubação nitrogenada na produção de mudas de sesbânia em substrato constituído de resíduos agroindustriais. Revista Árvore, v.27, n.4, p.443-449, 2003.

COUTINHO, M. P. et al. Crescimento de mudas de Sesbania virgata (Cav.) Pers. plantadas em uma área degradada por extração de argila. Revista Árvore, v.30, n.1, p.147-153, 2006.

DREYFUS, B.; GARCIA, J. L. \& GILLIS, M. Characterization of Azorhizobium caulinodans gen. nov., sp. nov., a stem-nodulating NitrogenFixing bacterium isolated from Sesbania rostrata.

International Journal of Systematic Bacteorology, v.38, n.1, p.89-98, 1988.
EMPRESA BRASILEIRA DE PESQUISA AGROPECUÁRIA - EMBRAPA. Centro Nacional de Pesquisa de Solos. Manual de métodos de análise de solos. 2.ed. Rio de Janeiro, 1997. 412p.

FARIA, S. M.; MELO, R. B. Obtenção de estirpes de rizóbio eficientes na fixação biológica de nitrogênio para espécies florestais. Seropédica: Embrapa Agrobiologia, 1998. p.1-4. (Recomendação Técnica, 3).

FRANCO, A. A. et al. Uso de leguminosas associadas a microrganismos na revegetação de áreas de mineração de bauxita em Porto-Trombetas-PA. Itaguaí: Embrapa Agrobiologia, 1996. 69p.

FRED, E. B.; WAKSMAN, S. A. Laboratory manual of general microbiology with special reference to the microorganisms of the soil. New York: McGraw-Hill Book Company, 1928. 145p.

GONÇALVES, M. \& MOREIRA, F. M. S. Specificity of the Legume Sesbania virgata (Caz.) Pers. and its Nodule Isolates Azorhizobium johannae with other Legume Hostes and Rhizobia. I. Symbiosis, v.36, n.1, p.57-68, 2004.

JACKMAN, P. J. H. Bacterial taxonomy based on electrophoretic whole-cell protein patterns. In: GOODFELLOW, M.; MINNIKIN, D. (Eds.). Chemical methods in bacterial systematics. London: Academic, 1985. p.119-129.

JENSEN, H. L. Nitrogen fixation in leguminous plants. I. General characters of root-nodule bacteria isolated from species of Medicago and Trifolium in Australia. Proceedings of the Linnean Society of New South Wales, v.66, n.1, p.98-102, 1942.

JESUS, E. C. et al. Avaliação de espécies de leguminosas como plantas-isca para o estudo da diversidade de bactérias que nodulam leguminosas. In: CONGRESSO DOS PÓSGRADUANDOS DA UFLA. UNIVERSIDADE FEDERAL DE LAVRAS, 14., 2005, Lavras. Resumo Expandido. Lavras, 2005. CD-ROOM

KISSMANN, K. G. Plantas infestantes e nocivas. São Paulo: BASF Brasileira, 1992. p.774-776.

R. Árvore, Viçosa-MG, v.33, n.2, p.215-226, 2009 
KISSMANN, K. G.; GROTH, D. Plantas

infestantes e nocivas. 2.ed. São Paulo: BASF Brasileira, 1999. p.947-950. Tomo II.

LAEMMLI, U. K. Cleavage of structural proteins during the assembly of the head of bacteriophage T4. Nature, v.227, p.680-685, 1970.

LIMA, A. S. et al. Nitrogen-fixing bacteria communities occurring in soils under different uses in the Western Amazon Region as indicated by nodulation of siratro (Macroptilium atropurpureum). Plant and Soil, v.20,p.1-19, 2009.

LORENZI, H. Plantas daninhas do Brasil: terrestres, aquáticas, parasitas e tóxicas. 3.ed. Nova Odessa: Instituto Plantarum, 2000.

MARTINEZ-ROMERO, E.; CABALLERO-

MELLADO, J. Rhizobium phylogenies and bacterial genetic diversity. Critical Reviews in Plant Sciences, v.15, n.2, p.113-140, 1996.

MOREIRA, F. M. S. et al. Characterization of rhizobia isolated from different divergence groups of tropical Leguminosae by comparative polyacrilamide gel electrophoresis of their total proteins. Systematic and Applied Microbiology, v.16, n.1, p.135-146, 1993.
MOREIRA, F. M. S. et al.. Azorhizobium doebereinerae sp. nov. Microsymbiont of Sesbania virgata (Caz.) Pers. Systematic and Applied Microbiology., v.29, n.1, p.197-206, 2006.

PotT, A.; POTT, V. J. Plantas do Pantanal. Corumbá: Embrapa/CPAP/SPI, 1994. 320p.

SCOTT, A. J.; KNOTT, M. A. Cluster analysis method for grouping means in the analysis of variance. Biometrics, v.30, n.3, p.507-512, 1974.

SILVA, M. F. ;CARREIRA, L.M.M.; TAVARES, A., S.; RIBEIRO, I.C.; JARDIM, M. A. A.G.; LOBO, M.G.A.; OLIVEIRA, J. Leguminosas da Amazônia brasileira: lista prévia. In; anais do XXXIX congresso Nacional de Botânica, v.2 n.1, p.193-237, 1989.

VINCENT, J. M. A manual for the pratical study of root-nodule bacteria. Oxford: Blackwell Scientific Publications, 1970. 164 p. (International Biological Programme Handbook, 15).

WOOMER, P.; SINGLETON, P. W.; BOHLOOL, B. B. Ecological indicators of native rhizobia in tropical soils. Applied and Environmental Microbiology, v.54, n.5, p.1112-1116, 1988. 